\title{
Tool-ply friction in thermoplastic composite forming
}

\author{
R.H.W. ten Thije, R. Akkerman, L. van der Meer, M. P. Ubbink
}

University of Twente - P.O. Box 217, 7500 AE Enschede, the Netherlands

URL:www.pt.ctw.utwente.nl, e-mail: R.H.W.tenthije@utwente.nl; R.Akkerman@utwente.nl

ABSTRACT: Friction is an important phenomenon that can dominate the resulting product geometry of thermoplastic composites upon forming. A model was developed that predicts the friction between a thermoplastic laminate and a rigid tool. The mesoscopic model, based on the Reynolds' equation for thin film lubrication, has been validated against experiments. The tool-ply friction was characterised for $2 \times 2$ twill/PP (Twintex) and 8 harness satin/PPS laminates. Tool-ply friction of the latter appears to be a combination of a Coulomb type of friction and a viscous type of friction.

KEYWORDS: Thermoplastic composite, friction

\section{INTRODUCTION}

Continuous fibre reinforced thermoplastics offer a cost reduction compared to thermosets due to promising fast production methods like diaphragm forming and rubber pressing. Their usage will increase in the future due to the evolving low cost manufacturing techniques for these products [7]. Friction is an important phenomenon that can dominate the resulting product geometry, fibre orientations and fibre stresses upon forming. Two types of friction can be distinguished. The first type is tool-ply friction, which occurs between the tool materials and the outer plies of the laminate. The second type is ply-ply friction, which occurs on the interface between the individual plies of a laminate. Forming experiments of pre-consolidated four-layer $8 \mathrm{H}$ satin weave PPS laminates on a dome geometry demonstrated that inter-ply friction is a dominant parameter in forming doubly curved components [9]. A thorough understanding of the frictional behaviour is necessary for the main objective of this research: optimisation of thermoplastic composite products. For the time being, the focus is on tool-ply friction.

\subsection{Review}

Most studies of the frictional behaviour of thermoplastic laminates have resulted in empirical models, based on elaborate testing of frictional properties in an experimental setup $[6,2,3,5,4]$. Many of the previous studies focused on Twintex, a woven composite material of commingled glass-polypropylene yarns. A proper starting point for an empirical law is the generalised Stribeck curve, as shown in figure 1. In this curve, the regions of Boundary Lubrication (BL), Mixed Lubrication (ML) and (Elasto)Hydrodynamic Lubrication $((\mathrm{E}) \mathrm{HL})$ are distinguished. The asperities of the contact surfaces touch in the BL region and bear the contact loads, while in the (E)HL region both surfaces are separated by a lubricant film in which shear occurs. The ML region is the transition region.

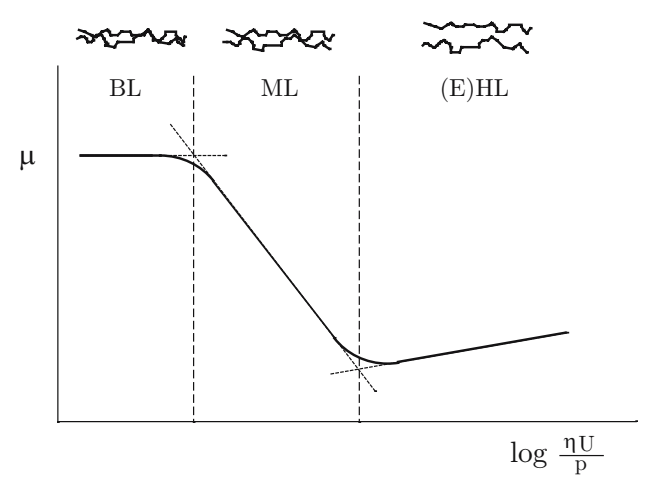

Figure 1: A generalised Stribeck curve.

A new mesoscopic approach was presented in the paper of Akkerman et. al. [1]. The film thickness was derived iteratively from the Reynolds' equation for thin film lubrication, rather than postulated as in earlier publications. The fabric geometry and the matrix material properties were used as the input parameters. The verification of the model was based on experimental results with Twintex. Here, we include the experimental results of a 8 harness satin weave based 
laminate with a PPS matrix (8HS/PPS) as well. The experimental results showed that only modelling the (E)HL region of the Stribeck curve is not sufficient for this material. An extension to the BL and ML region is necessary for an accurate friction model.

\section{EXPERIMENTS}

A pull-out setup was developed to characterise the tool-ply frictional behaviour of thermoplastic laminates at different velocities, temperatures and normal pressures. A schematic representation of this setup is shown in figure 2. The two pressure platens are heated and pressed against each other with the reinforced laminate in between. The laminate is then pulled from between the platens. The temperature $T$, normal force $N$, the displacement $u$ and the friction force $F_{f}$ are logged during the experiment. More details can be found in $[1,11,13]$.

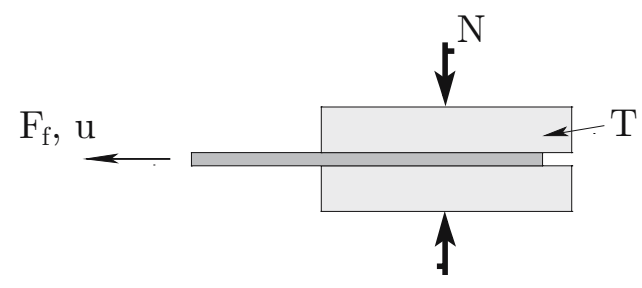

Figure 2: Schematic representation of the pull-out setup.

Pull-out experiments have been performed on two types of thermoplastic laminates:

1. Twintex TPEET44XXX ( $2 \times 2$ Twill / PP )

2. Ten Cate Cetex ${ }^{\circledR}$ SS303 (8H Satin / PPS )

Detailed information on the weaves can be found in table 1. Pre-consolidated laminates were cut into 300 x $100 \mathrm{~mm}$ strips and tested at different test conditions. The test matrix for the materials can be found in table 2. All tests were performed in triplicate.

Table 1: Fabric properties.

\begin{tabular}{lrcc}
\hline & & Twintex & 8HS/PPS \\
\hline \hline warp count & {$[\# / \mathrm{m}]$} & 377 & 2280 \\
\hline weft count & {$[\# / \mathrm{m}]$} & 168 & 2200 \\
\hline thickness & $\mathrm{mm}$ & 1.0 & 0.2375 \\
\hline
\end{tabular}

Table 2: Test conditions.

\begin{tabular}{lrccc}
\hline$U$ & {$[\mathrm{~mm} / \mathrm{min}]$} & 20 & 100 & 500 \\
\hline$n$ & {$[\mathrm{kPa}]$} & 21.05 & 42.11 & 63.16 \\
\hline$T$ Twintex & {$\left[{ }^{\circ} \mathrm{C}\right]$} & 180 & 200 & 220 \\
\hline$T$ 8HS/PPS & {$\left[{ }^{\circ} \mathrm{C}\right]$} & 305 & 332 & \\
\hline
\end{tabular}

The experiments result in curves, where the required pull-out force is plotted against the pull-out length. These curves typically show an initial peak force, after which a more or less steady state situation develops [1,8]. Figure 3 shows the resulting maximum and steady state friction coefficients found during the experiments at two distinct temperatures for both laminate types.

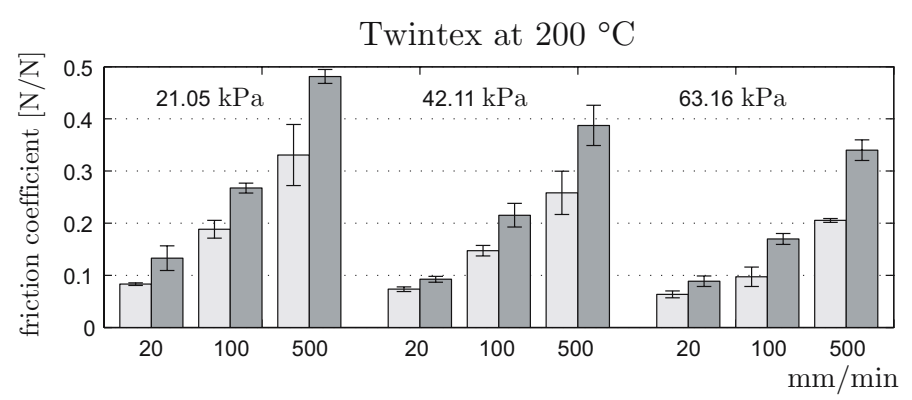

$8 \mathrm{HS} / \mathrm{PPS}$ at $305^{\circ} \mathrm{C}$

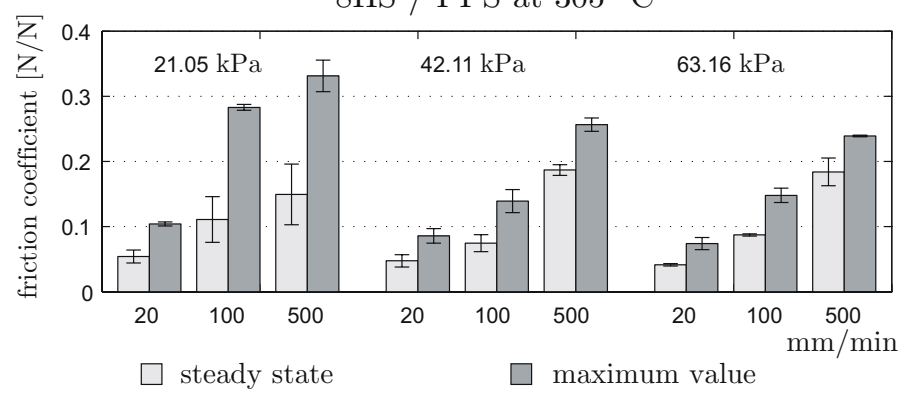

Figure 3: Experimental results of the pull-out experiment at different normal pressures and pull-out velocities. The error bars indicate the standard deviation.

\section{MODEL}

A mesoscopic model was used to simulate the toolply friction properties of arbitrary weave and matrix combinations. Figure 4 shows a schematic crosssection of a $2 \times 2$ twill weave when looking in the weft yarn direction.

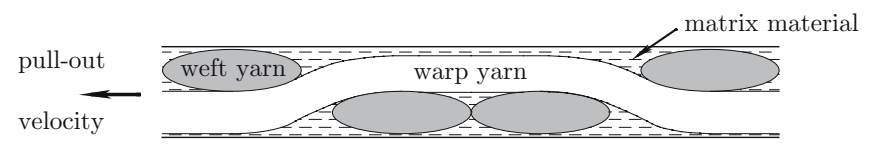

Figure 4: Schematic cross-section of a $2 \times 2$ twill weave.

Fully hydrodynamic lubrication is assumed between the yarns and the tool surface. The pressure in the matrix material starts to build up as it is squeezed in the wedge-shaped cavities between the weave and the tool surface. The matrix material separates the two surfaces and forms a viscous boundary layer. This 
process is governed by the Reynolds' equation, which for the one-dimensional steady state situation reads:

$$
\frac{\partial}{\partial x}\left(\frac{h^{3}}{\eta} \frac{\partial p}{\partial x}\right)=6 U \frac{\partial h}{\partial x}
$$

where $p$ denotes the pressure, $h$ the local film thickness, $\eta$ the viscosity and $U$ the slip velocity. The warp and weft yarn contours are discretised using elliptic equations, who's radii can be derived from the yarn count and consolidated laminate thickness. Warp and weft yarns are analysed separately and added up to the total response.

The viscosity is shear rate dependent and is modelled using a fit provided by the material manufacturer Ticona for the PPS material:

$$
\eta(T, \dot{\gamma})=a \cdot \dot{\gamma}^{b} \cdot e^{(c \cdot \dot{\gamma})} \cdot e^{\left(\frac{d}{T}\right)},
$$

with $\dot{\gamma}$ the shear rate. The viscosity of the PP material is modelled using a Cross-WLF model, of which the details can be found in [1]. The viscosity model parameters are given in table 3 . The previous publication [1] also provides details on the boundary conditions necessary to solve the Reynolds' equation for a given film thickness. An iterative procedure is then used to find the film thickness for which the total bearing force is equal to the externally applied normal force on the laminate.

\begin{tabular}{|c|c|c|c|c|}
\hline & \multicolumn{3}{|c|}{$\mathrm{PP}$} & PPS \\
\hline$n$ & {$[-]$} & 0.3973 & $\begin{array}{ll}\text { a } & {[-]}\end{array}$ & $1.56 \cdot 10^{-3}$ \\
\hline$\tau^{*}$ & {$[\mathrm{~Pa}]$} & 10987.6 & {$[-]$} & -0.0486 \\
\hline$D_{1}$ & {$[\mathrm{~Pa} \cdot \mathrm{s}]$} & $1.33454 \cdot 10^{14}$ & {$[-]$} & $-1.3 \cdot 10^{-4}$ \\
\hline$D_{2}$ & {$[\mathrm{~K}]$} & 263.15 & $\begin{array}{ll}\mathrm{d} & {[-]}\end{array}$ & 6892 \\
\hline$A_{1}$ & {$[-]$} & 32.17 & & \\
\hline$A_{2}$ & {$[\mathrm{~K}]$} & 51.6 & & \\
\hline
\end{tabular}

Table 3: Viscosity model parameters.

\section{RESULTS AND DISCUSSION}

The steady state friction coefficient for both laminate types at a fixed temperature and normal pressure are plotted at the top of the figures 5 and 6 . The corresponding film thickness prediction is plotted at the bottom. The figures contain experimental data from additional test with varying pull-out velocities as well. In the stepped speed experiments, the velocity was kept constant for a short period and increased again. During the variable speed experiments, the velocity was changed continuously.
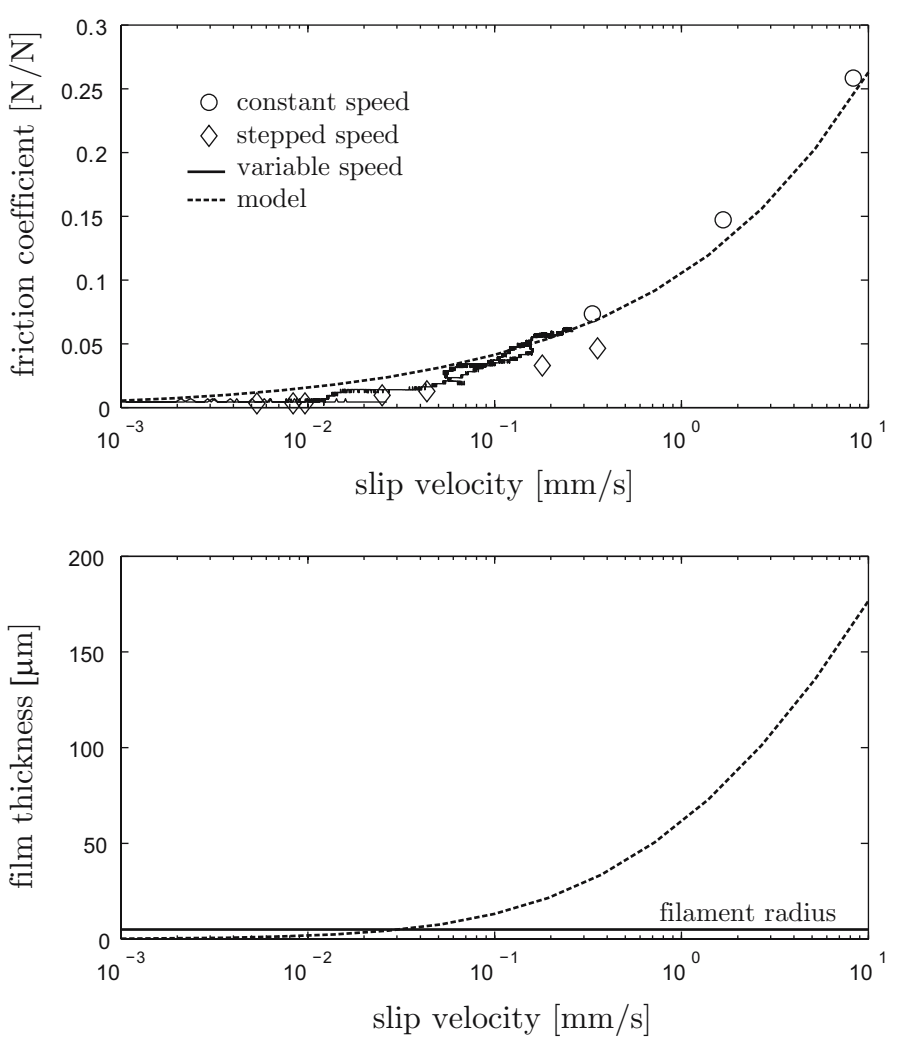

Figure 5: Top: Stribeck curve for Twintex at a normal pressure of $42.11 \mathrm{kPa}$ and a temperature of $200^{\circ} \mathrm{C}$. Bottom: film thickness prediction.
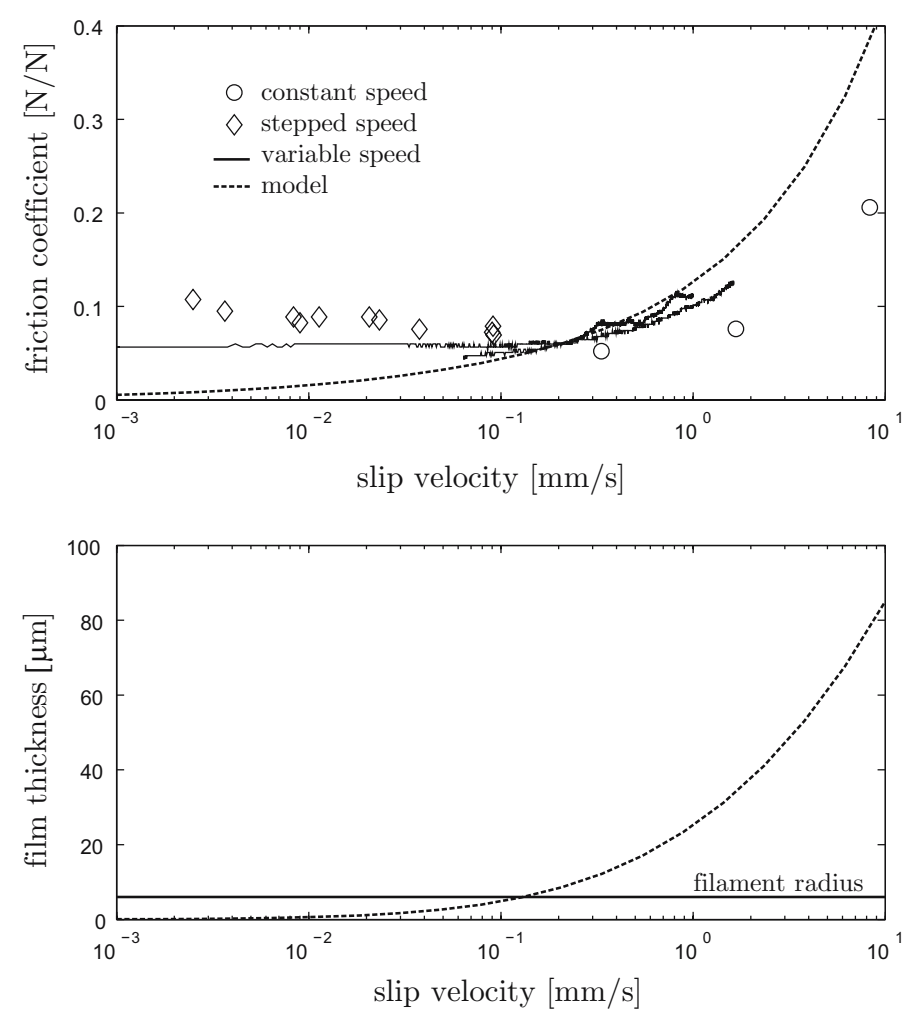

Figure 6: Top: Stribeck curve for $8 \mathrm{HS} / \mathrm{PPS}$ at a normal pressure of $42.11 \mathrm{kPa}$ and a temperature of $305^{\circ} \mathrm{C}$. Bottom: film thickness prediction. 
The experimental results and the simulated results correspond well for the Twintex material, as already shown in [1]. The simulated results fit the experimental results found by other researchers as well [5]. The experimental and simulated results of the $8 \mathrm{HS} / \mathrm{PPS}$ laminate show less correspondence. The model overpredicts the coefficient of friction with a factor of two in the EHL region. The experimental results indicate that the friction enters the BL and/or ML regions of the Stribeck curve at velocities below $0.1 \mathrm{~mm} / \mathrm{s}$. In this region, the coefficient of friction increases only slightly with a decreasing slip velocity. The absence of a significant increase when entering the BL region has been observed before in polymer based lubricants [10].

The mesoscopic EHL model can be expected to break down when the surface roughness is not negligible compared to the film thickness. The film thickness ratio $\Lambda$ can be used [12] to estimate the corresponding film thickness at which the two surfaces make contact during a decreasing velocity:

$$
\Lambda=\frac{h}{\sqrt{R_{1}^{2}+R_{2}^{2}}},
$$

where $R_{1}$ and $R_{2}$ are the average surface roughnesses. At $\Lambda<1$ boundary lubrication prevails, as full film lubrication occurs at $\Lambda>3 . .4$. The average surface roughness of the polished platens is estimated at $0.1 \mu \mathrm{m}$. If the surface of the yarn consist of stacked fibre filaments, the average surface roughness of the yarn equals $0.275 R_{f}$, with $R_{f}$ the filament radius of $12 \mu \mathrm{m}$. The transition to the full film lubrication occurs at the point where the film thicknesses roughly equals the filament radius. This transition point is indicated in the figures 5 and 6 as well and corresponds to the start of the EHL region.

\section{CONCLUSIONS AND OUTLOOK}

Temperature, normal pressure and sliding velocity are the dominant parameters in tool-ply friction of thermoplastic laminates. The developed model to predict the amount of friction is only valid in the region of fully lubricated friction, but can predict the transition point to the mixed and boundary lubrication regions as well. The experimentally determined coefficients of friction and the simulated results correspond very well for the Twintex $(2 \times 2$ twill/PP) material. The results for the 8 harness satin/PPS weave were overpredicted by a factor of two by the model, although the transition point between mixed lubrication and fully lubricated friction could be predicted.
Additional experiments on other fabric types are necessary to validate the model. It could be that the one-dimensional model is accurate enough for the coarse Twintex weave, but is not for the delicate 8 harness satin weave. Pull-out experiments will be performed on idealised surfaces to verify the validity of the Reynolds' equation for lubricated friction with thermoplastics.

\section{ACKNOWLEDGEMENT}

The support of the NIVR, Stork Fokker AESP and Ten Cate Advanced Composites is gratefully acknowledged by the authors.

\section{REFERENCES}

[1] R. Akkerman, M. P. Ubbink, M. B. de Rooij, and R. H. W. ten Thije. Tool-ply friction in composite forming. In Proc 10th Int ESAFORM Conf, 2007.

[2] J. Gorczyca. A Study of the Frictional Behaviour of a Plain-Weave Fabric During the Thermoforming Process. $\mathrm{PhD}$ thesis, University of Massachusetts Lowell (USA), 2004.

[3] Jennifer L. Gorczyca-Cole, James A. Sherwood, and Julie Chen. A friction model for thermostamping commingled glasspolypropylene woven fabrics. Compos Part A-Appl S, 38:393-406, 2007.

[4] Gilbert Lebrun, Martin N. Bureau, and Johanne Denault. Thermoforming-stamping of continuous glass fiber/polypropylene composites: Interlaminar and toollaminate shear properties. J Thermoplast Compos, 17:137165, 2004.

[5] H. Lin, P. Harrison, K. van de Haar, A. C. Long, R. Akkerman, and M. J. Clifford. Investigation of tool-ply friction of viscous textile composites. In Proc TEXCOMP-8, 2006. CD-edition.

[6] A. M. Murtagh, M. R. Monaghan, and P. J. Mallon. Investigation of the interply slip process in continuous fibre thermoplastic composites. In Proc 9th ICCM Conf, 1993.

[7] Arnt R. Offringa. Thermoplastic composites - rapid processing applications. Compos Part A-Appl S, 27:329-336, 1996.

[8] T. Phung, R. Paton, and A. P. Mouritz. Characterisation of the interply shearing resistance of carbonepoxy unidirectional tape and fabric prepregs. In Proc 6th Int ESAFORM Conf, pages 867-870. Nuova Ipsa Editore, Palermo, Italy, 2003. ISBN 88-7676-211-6.

[9] R. H. W. ten Thije. Forming simulation of laminated composite forming processes. $\mathrm{PhD}$ thesis, University of Twente, 2007. ISBN 978-90-365-2546-6.

[10] Ching-Fang Tu and Tomlinson Fort. A study of fibercapstan friction. 1. Stribeck curves. Tribol Int, 37:701-710, 2004.

[11] M. P. Ubbink. Tool-ply friction of woven fabric composites. Master's thesis, University of Twente, 2006.

[12] Anton van Beek. Machine lifetime performance and reliability. University of Delft, 2004. ISBN 90-3700-208-0.

[13] L. van der Meer. 2.5d modelling and validation of tool-ply friction. Master's thesis, University of Twente, 2007. 